\title{
Inkjet Catalyst Printing and Electroless Copper Deposition for Low-Cost Patterned Microwave Passive Devices on Paper
}

\author{
Benjamin S. Cook, ${ }^{1 \dagger}$ Yunnan Fang, ${ }^{2 \dagger}$ Sangkil Kim, ${ }^{1}$ Taoran Le, ${ }^{1}$ W. Brandon Goodwin, ${ }^{2}$ \\ Kenneth H. Sandhage, ${ }^{2,3, *}$ and Manos M. Tentzeris ${ }^{1, *}$ \\ ${ }^{1}$ School of Electrical and Computer Engineering, Georgia Institute of Technology, Atlanta, GA 30332, USA \\ ${ }^{2}$ School of Materials Science and Engineering, Georgia Institute of Technology, Atlanta, GA 30332, USA \\ ${ }^{3}$ School of Chemistry and Biochemistry, Georgia Institute of Technology, Atlanta, GA 30332, USA
}

(received date: 1 February 2013 / accepted date: 20 February 2013 / published date: )

\begin{abstract}
A scalable, low-cost process for fabricating copper-based microwave components on flexible, paper-based substrates is demonstrated. An inkjet printer is used to deposit a catalyst-bearing solution (tailored for such printing) in a desired pattern on commercially-available, recyclable, non-toxic $\left(\right.$ Teslin $\left.^{\circledR}\right)$ paper. The catalystbearing paper is then immersed in an aqueous copper-bearing solution to allow for electroless deposition of a compact and conformal layer of copper in the inkjet-derived pattern. Meander monopole antennas comprised of such electroless-deposited copper patterns on paper exhibited comparable performance as for antennas synthesized via inkjet printing of a commercially-available silver nanoparticle ink. However, the solutionbased patterning and electroless copper deposition process avoids nozzle-clogging problems and costs associated with noble metal particle-based inks. This process yields compact conductive copper layers without appreciable oxidation and without the need for an elevated temperature, post-deposition thermal treatment commonly required for noble metal particle-based ink processes. This low-cost copper patterning process is readily scalable and may be used to generate a variety of copper-based microwave devices on flexible, paper-based substrates.
\end{abstract}

Keywords: inkjet printed electronics, copper metallization, flexible substrates, antennas, RF devices, paperbearing electronics

\section{INTRODUCTION}

Inkjet printing is a patterning technology that has been generating increased interest for the fabrication of metalized components and devices, due to its low cost, scalability, maskless and purely additive nature (thereby avoiding chemical etchants and reducing material waste), and applicability to a wide variety of deposited metals and substrates, including flexible low-cost substrates such as paper. $^{[1-4]}$ Reports of inkjet-printed metalized devices on flexible substrates range from antennas to sensors to thin film transistors to RFID tags. ${ }^{[1,5-14]}$

The patterned metallization of substrates using inkjet printing is commonly conducted with inks comprised of a dispersion of metallic nanoparticles within a carrier fluid tailored to achieve a desired viscosity and wetting behavior for a particular substrate. ${ }^{[1-4]}$ Coatings on the metallic nanoparticles are used to ensure that the nanoparticles remain well dispersed in the ink.$^{[1-3]}$ After inkjet printing, however, a

*Corresponding author: ken.sandhage@mse.gatech.edu

*Corresponding author: emmanouil.tentzeris@ece.gatech.edu

${ }^{\dagger}$ These two authors contributed equally to this work.

CKIM and Springer thermal treatment is needed to remove such coatings and to allow for nanoparticle necking, so as to yield patterned metallic films of desired electrical conductivity. ${ }^{[1,3,10,15,16]}$ Except for the case of gold, such thermal treatments in air can result in significant oxidation of the metallic nanoparticles, particularly for relatively inexpensive non-noble metals, such as copper. ${ }^{[1,17-23]}$ While inert or reducing gas atmospheres could be used to minimize or avoid such oxidation, processes that avoid such inert gas thermal treatments would be preferred for scalable manufacturing.

In this paper, we demonstrate a low-cost, inkjet patterning method for generating copper-based devices on commerciallyavailable recyclable, non-toxic $\left(\operatorname{Teslin}^{\circledR}\right)$ paper that avoids the need for nanoparticle inks. The performance of a $2.4 \mathrm{GHz}$ meander monopole antenna comprised of such patterned copper on paper is compared to a similar silver-based antenna synthesized via inkjet printing of a commerciallyavailable nanoparticle ink.

\section{EXPERIMENTAL PROCEDURE}

2.1 Palladium Chloride Catalyst Solution, Electroless Copper Solution, Silver Nanoparticle Ink, and Teslin ${ }^{\circledR}$ Paper

A homogeneous palladium(II) chloride catalyst solution 
was prepared as follows. A $10 \mathrm{mg}$ batch of $\mathrm{PdCl}_{2}(99.999 \%$ purity, Alfa Aesar, Ward Hill, MA) was added to $40 \mathrm{~mL}$ of anhydrous ethanol and stirred at $30 \mathrm{rpm}$ for $2 \mathrm{~h}$ at room temperature. After removal of undissolved $\mathrm{PdCl}_{2}$ by centrifugation (9000 rpm, $2 \mathrm{~min}$ ), the supernatant was isolated and passed through a $0.2 \mu \mathrm{m}$ filter (Fujifilm Dimatix, Inc., Santa Clara, CA, USA). The homogeneous supernatant was then mixed with an aqueous solution of $50 \mathrm{wt}$. \% glycerol to increase the viscosity to $12.1 \mathrm{cP}$ at room temperature (as determined with a Gilmont ${ }^{\mathbb{E}}$ Falling Ball Viscometer, ColePalmer, Vernon Hills, IL, USA) in order to allow for use of the Dimatix DMP-2800 print nozzle described below. ${ }^{[24]}$

The copper-bearing bath for electroless deposition was comprised of an aqueous solution of $0.19 \mathrm{M}$ cupric sulfate (anhydrous $\mathrm{CuSO}_{4}$, Mallinckrodt Baker, Phillipsburg, NJ, USA) with $0.67 \mathrm{M}$ sodium potassium tartrate tetrahydrate $\left(\mathrm{C}_{4} \mathrm{H}_{4} \mathrm{KNaO}_{6} \cdot 4 \mathrm{H}_{2} \mathrm{O}\right.$, Alfa Aesar). After adjusting the $\mathrm{pH}$ of this solution to 12.5 using an aqueous $\mathrm{NaOH}$ solution, formaldehyde (37\% in water, Alfa Aesar) was added at a concentration of $220 \mathrm{mM}$. This solution was then passed through a $0.2 \mu \mathrm{m}$ filter to remove contaminant particles.

A commercial ink comprised of $20 \mathrm{wt}$ \% silver nanoparticles of 30-50 nm size (CCI-300, Cabot Corp., Boston, MA, USA) was used in the as-received state for inkjet printing. ${ }^{[25]}$

Teslin $^{\circledR}$ paper (Brainstorm Enterprises, Southbridge, MA USA) was used in the as-received state as a flexible substrate for electroless copper and silver nanoparticle deposition.

\subsection{Inkjet Printing of the Palladium Chloride Catalyst Solution and Ag Nanoparticle Ink}

The $\mathrm{PdCl}_{2}$ solution was loaded into a nozzle cartridge of a commercial, drop-on-demand inkjet printer (DMP-2800, Fujifilm Dimatix, Inc., Santa Clara, CA USA). The nominal volume and nominal diameter of each drop deposited from the cartridge were $10 \mathrm{pL}$ and $40 \mathrm{~mm}$, respectively. Inkjet printing was conducted with a cartridge temperature of $37.5^{\circ} \mathrm{C}$ (to lower the solution viscosity to $7.4 \mathrm{cP}$ ) with the paper substrate held at $40^{\circ} \mathrm{C}$ (to enhance the rate of ethanol evaporation from the deposited droplets). A single layer of the catalyst solution was printed on the Teslin ${ }^{\circledR}$ substrate with a drop spacing of $20 \mu \mathrm{m}$ (1270 DPI) to allow for overlap of the droplets.

A similar procedure was followed for the deposition of the commercial silver nanoparticle ink, except that up to 5 layers of printed ink were sequentially deposited. For the silvercoated paper specimens, a thermal treatment was conducted at $120^{\circ} \mathrm{C}$ for $1 \mathrm{~h}$ in air to allow for removal of organic material from the silver nanoparticle surfaces and for some nanoparticle necking (sintering).

\subsection{Electroless Copper Deposition}

The palladium chloride-bearing $\operatorname{Teslin}^{\circledR}$ paper was immersed in the electroless copper solution at room temperature for times of 10 to $50 \mathrm{~min}$ to allow for varied amounts of copper deposition. The resulting copper-coated paper was then immersed in DI water for $1 \mathrm{~min}$ and dried in flowing air at room temperature for $5 \mathrm{~min}$.

\subsection{Materials Characterization}

Polished cross-sections of copper and silver films on $\operatorname{Teslin}^{\circledR}$ paper were created by encapsulating the specimens within an epoxy resin, followed by grinding and polishing with a series of SiC-bearing polishing papers and then diamond pastes to a final surface finish of $0.25 \mu \mathrm{m}$. Scanning electron microscopy was conducted with a field emission scanning electron microscope (Leo 1530 FEG SEM, Carl Zeiss SMT Ltd., Cambridge, UK) equipped with an energy dispersive $x$-ray spectrometer (INCA EDS, Oxford Instruments, Bucks, UK). X-ray diffraction analyses (X-Pert Pro Alpha 1 diffractometer, PANalytical, Almelo, The Netherlands) were conducted with $\mathrm{Cu} K \alpha$ radiation using an incident beam Johannsen monochromator and an Xcelerator linear detector.

\subsection{Dielectric Characterization}

The permittivity $\left(\varepsilon_{r}\right)$ and loss tangent $(\tan \delta)$ of the Teslin ${ }^{\circledR}$ paper were determined via the microstrip T-resonator method. ${ }^{[26-29]}$ The microstrip T-resonator is a transmission line with an open circuit stub which has a null in the insertion loss resulting from destructive interference of the reflected wave from the stub with the incident wave, which occurs when the value of the stub length corresponds to $\lambda / 4$ (at the resonant frequency). The resonant frequency was determined by Eq. (1) below, where $n$ is the resonance mode (i.e., $n=1,3,5, \ldots$ ), $c$ is the speed of light in free space, $L$ is the length of the open circuit stub, $L_{0}$ is the correction factor for the fringing capacitance at the end of the stub, and $\varepsilon_{e f f, n}$ is the effective permittivity of the microstrip line. ${ }^{[2]}$

$$
f_{r, n}=\frac{n c}{4\left(L+L_{0}\right) \sqrt{\varepsilon_{e f f, n}}} .
$$

The effective permittivity, $\varepsilon_{\text {eff }, n}$, was then used to obtain the relative permittivity, $\varepsilon_{r, n}$, using Eqs. (2) and (3). ${ }^{[2]}$

$$
\varepsilon_{e f f, n}= \begin{cases}\frac{\varepsilon_{r, n}+1}{2}\left[1-\frac{1}{2 H^{\prime}}\left(\frac{\varepsilon_{r, n}-1}{\varepsilon_{r, n}+1}\right)\left(\ln \frac{\pi}{2}+\frac{1}{\varepsilon_{r, n}} \ln \frac{4}{\pi}\right)\right]^{-2} & \frac{w}{h}<1.3 \\ \frac{\varepsilon_{r, n}+1}{2}+\frac{\varepsilon_{r, n}-1}{2}\left(1+10 \frac{h}{w}\right)^{-0.555} & \frac{w}{h}>1.3\end{cases}
$$

where:

$$
H^{\prime}=\ln \left(4 \frac{h}{w}+\sqrt{16\left(\frac{h}{w}\right)^{2}+2}\right)
$$

with $h$ and $w$ referring to the laminate thickness and the 
width of the feeder lines, respectively.

The loss tangent of the substrate, $\tan \delta$, was obtained from the quality factor, $Q$, associated with the primary and higher order resonances. The loaded $Q$-factor, $Q_{l, n}$ (i.e., the $Q$ obtained without removing the load due to connected measurement equipment), was calculated using Eq. (4).

$$
Q_{l, n}=\frac{f_{r, n}}{B W_{3 d B, n}} .
$$

The $Q_{l, n}$ value was then converted to the unloaded Qfactor, $Q_{u l, n}$, using Eq. (5), where $B W_{3 d B, n}$ refers to the $3 \mathrm{~dB}$ bandwidth of the nth mode and $L_{a}$ is the insertion loss (in $\mathrm{dBs}$ ) at the corresponding resonance $n$.

$$
Q_{u l, n}=\frac{Q_{l, n}}{\sqrt{1-2 \times 10^{L_{a} / 10}}} .
$$

The unloaded Q-factor, $Q_{u l, n}$, was then inserted into Eq. (6) to obtain the total loss, $\alpha_{t o t, n}$ (in $\mathrm{dB} / \mathrm{m}$ ).

$$
\alpha_{t o t, n}=\alpha_{c, n}+\alpha_{d, n}+\alpha_{r, n}=\frac{8.686 \pi f_{r, n} \sqrt{\varepsilon_{e f f, n}}}{c Q_{u l, n}} .
$$

The value of dielectric loss, $\alpha_{d, n}$, was obtained by subtracting the value of the conductor loss, $\alpha_{c, n}$ (calculated using Agilent's Line-Calc software), from the total loss, $\alpha_{10 t, n}$, and ignoring the radiation loss, $\alpha_{r, n}$ (which should be quite small, given the 260 um thickness of the paper substrate, over the measured frequency range). ${ }^{[27]}$ The value of the loss tangent, $\tan \delta$, was then calculated from Eq. (7), where $\lambda_{0}$ is the free space wavelength. ${ }^{[27]}$

$$
\tan \delta=\frac{\alpha_{d, n} \lambda_{0} \sqrt{\varepsilon_{e f f, n}}\left(\varepsilon_{r, n}-1\right)}{8.686 \pi \varepsilon_{r, n}\left(\varepsilon_{e f f, n}+1\right)} .
$$

Dielectric measurements were obtained with an $8 \mathrm{GHz}$ vector network analyzer (ZVA-8, Rohde and Schwarz, Munich, Germany).

\subsection{Antenna Simulation and Characterization}

A Satimo Stargate chamber (Satimo, Kennesaw, GA, USA) was used to measure the radiation patterns of the $\mathrm{Cu}$ and Ag meandering monopole antennas. With this chamber, the antenna was kept stationary and the vertical and horizontal polarizations of the radiated field were evaluated a 3-D spatially distributed array of probes.

\section{RESULTS AND DISCUSSION}

\subsection{Structural and Electrical Characterization of the Patterned Copper and Silver on Teslin ${ }^{\circledR}$ Paper}

Teslin ${ }^{\circledR}$ paper, a waterproof, petroleum-free formulation comprised of a polyolefin base blended with silica, can be an attractive flexible substrate for devices, owing to its commercial availability, low cost, recyclability, lack of toxicity, and high strength relative to other papers and organic substrates. ${ }^{[30]}$ The inkjet printing of a homogeneous solution of palladium chloride on Teslin ${ }^{\mathbb{B}}$ paper was used in this work to induce the patterned electroless deposition of copper on this flexible substrate. Such a precipitate-free printing approach eliminates problems associated with the use of noble-metal-particle-based printing. While catalyzed electroless deposition is well known, ${ }^{[31-36]}$ tailoring of the palladiumbearing catalyst solution was required in the present work to allow for inkjet printing of desired patterns on the Teslin ${ }^{\circledR}$ paper substrate. Ethanol was chosen as the solvent for the palladium chloride catalyst owing to the enhanced wetting observed for this solvent, relative to water, on Teslin ${ }^{\circledR}$ paper. Exposure of ethanol droplets to the Teslin ${ }^{\circledR}$ paper resulted in complete infiltration of the droplets into the paper within a few seconds, whereas water droplets were found to ball up upon contact with the paper and then roll off upon tilting of the paper within a few seconds after contact. However, in order to reduce the rate of spreading of the ethanol-based catalyst solution through the paper (so as to enhance the printing resolution), the viscosity of the catalyst solution was increased through the addition of glycerol. The heating of the substrate during printing was also used to enhance the rate of ethanol evaporation and to decrease the rate of spreading of the palladium chloride catalyst solution through/ across the Teslin ${ }^{\mathbb{B}}$ paper.

Representative secondary electron (SE) images of topdown and cross-sectional views of copper and silver films are shown in Fig. 1. The $\mathrm{Cu}$ film was generated by inkjet printing of the $\mathrm{PdCl}_{2}$-bearing catalyst solution, followed by exposure to the $\mathrm{Cu}$-bearing electroless solution for $10 \mathrm{~min}$ at room temperature. The Ag nanoparticle-based film was prepared by inkjet printing of 1 layer, and then thermally treated for $1 \mathrm{~h}$ in air at $120^{\circ} \mathrm{C}$. The images in Fig. 1 indicate that the copper and silver films were continuous, conformed to the surface of the Teslin ${ }^{\circledR}$ paper, and were comprised of nanoparticles. X-ray diffraction (XRD) and energy-dispersive X-ray (EDX) analyses of such films are shown in Fig. 2. Both films were comprised predominantly of metallic copper and silver (i.e., the thermal treatment of the silver nanoparticle films in air at $120^{\circ} \mathrm{C}$ did not result in appreciable detectable silver oxide formation). Scherrer analyses of the XRD patterns yielded average crystallite sizes of $33 \mathrm{~nm}$ and $21 \mathrm{~nm}$ for the $\mathrm{Cu}$ and $\mathrm{Ag}$ films, respectively. The average thicknesses of these metallic films were also obtained as a function of the electroless deposition time (for $\mathrm{Cu}$ films) and the number of inkjet printed layers (for $\mathrm{Ag}$ films), and these values are shown in Table 1.

The sheet resistance values of $\mathrm{Cu}$ and $\mathrm{Ag}$ test strips $(2 \mathrm{~mm}$ wide $\times 10 \mathrm{~mm}$ long) were measured using the four point probe method, and these values are shown in Fig. 3 and Table 1. With increasing electroless deposition time, the conformal $\mathrm{Cu}$ films increased in thickness and the sheet 
(a)

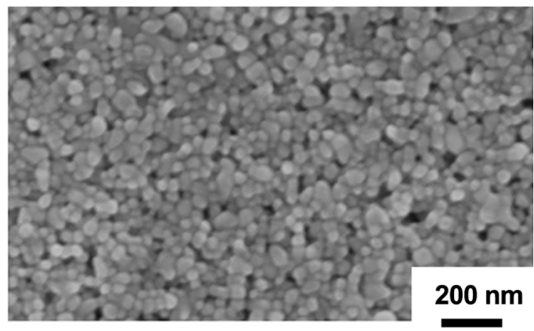

(b)

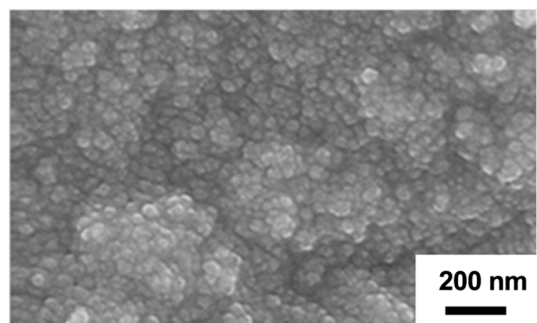

(c)

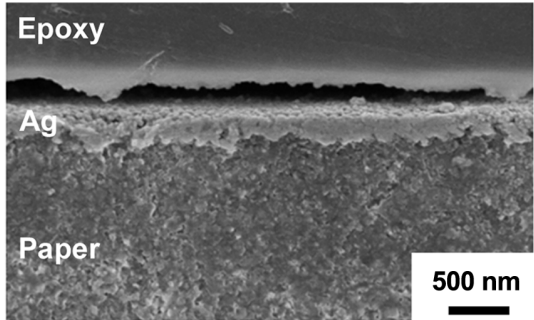

(d)

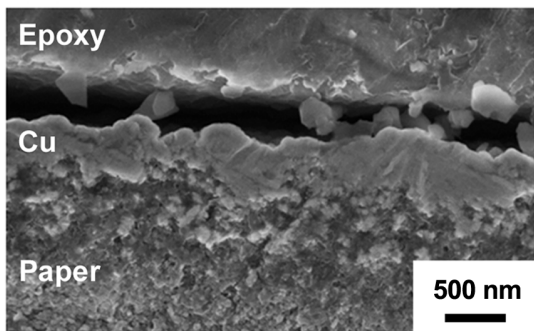

(e)

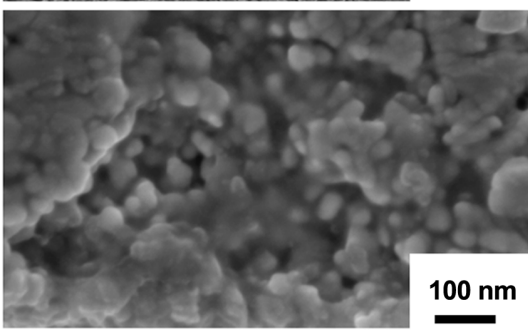

(f)

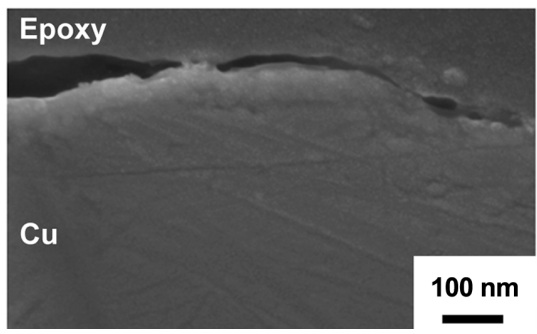

Fig. 1. SE images of: (a), (c), (e) an Ag film prepared by inkjet printing of 1 nanoparticle layer on Teslin ${ }^{\circledR}$ paper followed by heat treatment for $1 \mathrm{~h}$ at $120^{\circ} \mathrm{C}$, and (b), (d), (f) a Cu film on Teslin ${ }^{\circledR}$ paper prepared by inkjet printing of the $\mathrm{PdCl}_{2}$ solution, followed by electroless $\mathrm{Cu}$ deposition for $10 \mathrm{~min}$. Top-down images are shown in (a) and (b), with cross-sectional images shown in (c)-(f). (Note: the metal films delaminated from the mounting epoxy during polishing.)
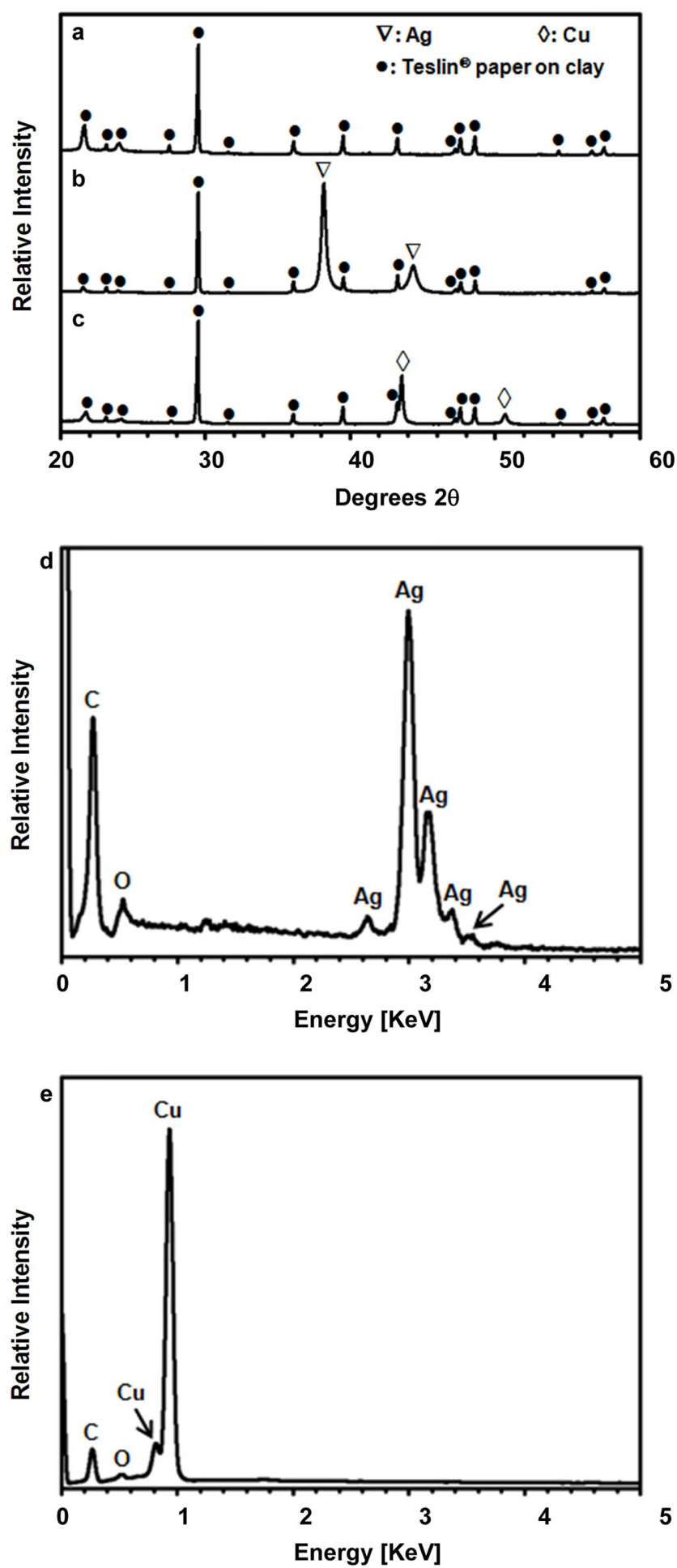

Fig. 2. XRD analyses of: (a) Teslin ${ }^{\circledR}$ paper held on a clay backing, (b) an Ag nanoparticle film prepared by inkjet printing of 3 nanoparticle layers on Teslin ${ }^{\circledR}$ paper followed by heat treatment for $1 \mathrm{~h}$ at $120^{\circ} \mathrm{C}$ (held on a clay backing), and (c) a Cu film on Teslin ${ }^{\circledR}$ paper prepared by inkjet printing of the $\mathrm{PdCl}_{2}$ solution, followed by electroless $\mathrm{Cu}$ deposition for $50 \mathrm{~min}$ (held on a clay backing). EDX analyses of: (d) an $\mathrm{Ag}$ nanoparticle film of the type in (b), and (e) a Cu film of the type in (c). 
Table 1. Electrical characterization of $\mathrm{Cu}$ and $\mathrm{Ag}$ test strips.

\begin{tabular}{lccc}
\hline \hline $\begin{array}{c}\text { Specimen } \\
\text { Type* }\end{array}$ & $\begin{array}{c}\text { Average } \\
\text { Thickness } \\
(\mu \mathrm{m})\end{array}$ & $\begin{array}{c}\text { Sheet } \\
\text { Resistance } \\
(\Omega / \square)\end{array}$ & $\begin{array}{c}\text { Electrical } \\
\text { Conductivity } \\
(\mathrm{S} / \mathrm{m})\end{array}$ \\
\hline $\mathrm{Cu} / 10 \mathrm{~min}$ & $0.61 \pm 0.13$ & 7.6 & $2.2 \times 10^{5}$ \\
$\mathrm{Cu} / 50 \mathrm{~min}$ & $3.87 \pm 0.90$ & 0.099 & $3.4 \times 10^{6}$ \\
$\mathrm{Ag} / 1$ layer/1 h & $0.49 \pm 0.08$ & 4.6 & $4.4 \times 10^{5}$ \\
$\mathrm{Ag} / 3$ layers$/ 1 \mathrm{~h}$ & $1.35 \pm 0.16$ & 0.63 & $1.2 \times 10^{6}$ \\
$\mathrm{Ag} / 5$ layers$/ 1 \mathrm{~h}$ & $2.39 \pm 0.10$ & 0.20 & $2.1 \times 10^{6}$ \\
$\mathrm{Ag} / 5$ layers$/ 2 \mathrm{~h}$ & $2.39 \pm 0.10$ & 0.15 & $2.8 \times 10^{6}$ \\
\hline
\end{tabular}

*The time of electroless deposition is indicated for the $\mathrm{Cu}$ films. The number of inkjet printed layers is indicated for the Ag films (all of which were thermally treated at $120^{\circ} \mathrm{C}$ for $1 \mathrm{~h}$ or $2 \mathrm{~h}$ in air).

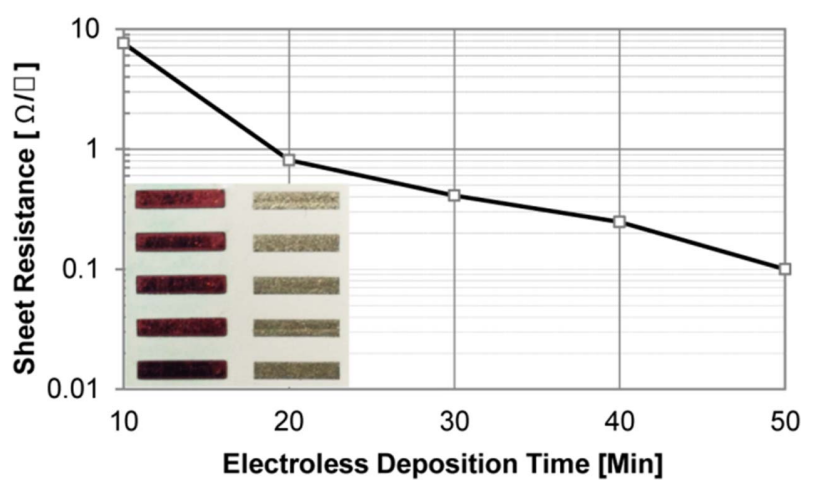

Fig. 3. Sheet resistance values of $\mathrm{Cu}$ films, in the form of test strips on Teslin ${ }^{\circledR}$ paper, as a function of the exposure time to the $\mathrm{Cu}$ electroless deposition solution (after via inkjet printing of the $\mathrm{PdCl}_{2}$ solution). Inset: optical images of $\mathrm{Cu}$ test strips (left, formed with increasing electroless deposition time from top to bottom) and $\mathrm{Ag}$ test strips (right, formed with increasing numbers of inkjet printed nanoparticle layers from top to bottom).

resistance values of these test strips decreased. A reduction in sheet resistance with an increase in the numbers of printed nanoparticle layers was also observed for the $\mathrm{Ag}$ test strips. Comparison of the data in Table 1 for the $\mathrm{Cu}$ and $\mathrm{Ag}$ test strips indicated that the $\mathrm{Cu}$ specimens possessed roughly comparable values of electrical conductivity $\left(10^{5}-10^{6} \mathrm{~S} / \mathrm{m}\right)$ as for the $\mathrm{Ag}$ specimens. Given the appreciably lower materials cost (by about one order of magnitude) associated with the electroless $\mathrm{Cu}$ deposition process relative to the $\mathrm{Ag}$ nanoparticle ink process, and the shorter time required to prepare large area, relatively thick $(\geq 3 \mu \mathrm{m})$ films of electroless-deposited $\mathrm{Cu}$ than of $\mathrm{Ag}$ nanoparticles (due to the longer time required for sequential large area printing of multiple nanoparticle layers than for sustained large area electroless deposition), the ability to achieve comparable values of conductivity makes the $\mathrm{Cu}$ electroless deposition process quite attractive.

\subsection{Teslin ${ }^{\circledR}$ Paper Characterization}

In order to be able to design microwave structures and (a)

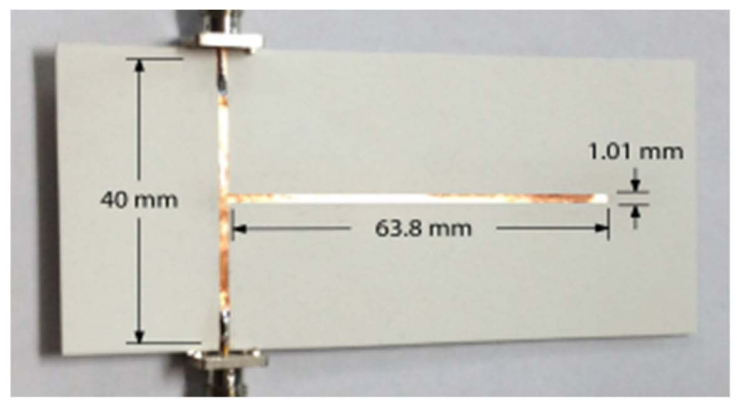

(b)

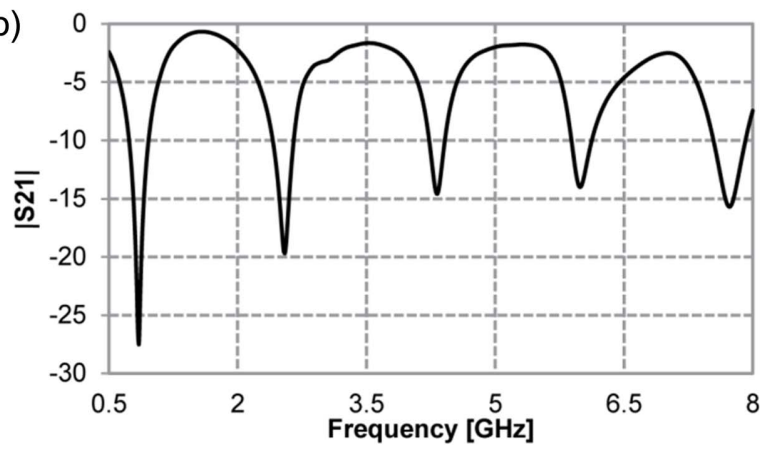

(c)

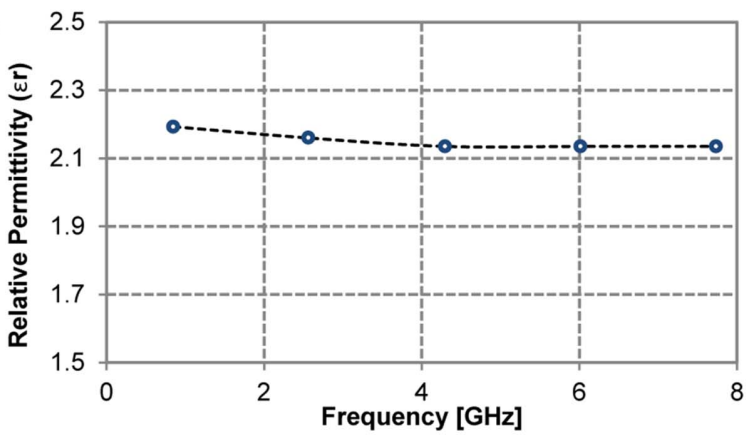

(d)

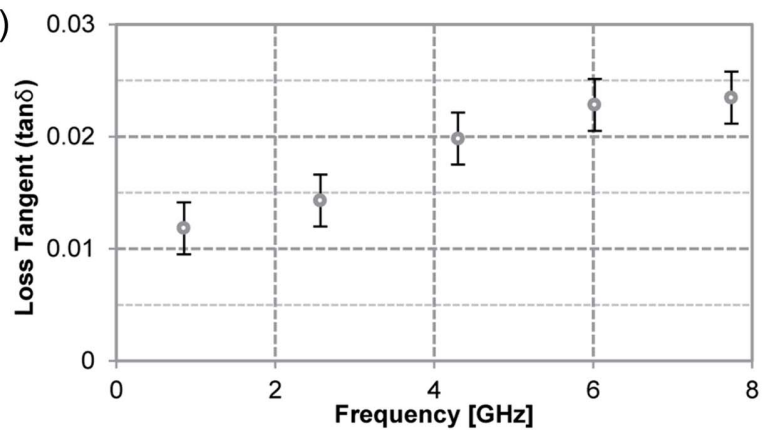

Fig. 4. (a) Optical image of the fabricated $\mathrm{Cu}$ microstrip T-resonator on Teslin ${ }^{\circledR}$ paper. Plots of the frequency dependence of: (b) the measured insertion loss (S21) of the fabricated T-resonator, (c) the extracted relative permittivity of the Teslin ${ }^{\circledR}$ paper, and (d) the extracted loss tangent of the Teslin ${ }^{\circledR}$ paper.

antennas using patterned $\mathrm{Cu}$ structures (via the present electroless deposition process) on a Teslin ${ }^{\circledR}$ paper substrate, the relative permittivity $\left(\varepsilon_{r}\right)$ and loss tangent $(\tan \delta)$ of the Teslin ${ }^{\circledR}$ paper needed to be determined as a function of 
frequency. Several approaches for evaluating the permittivity and loss of substrates commonly found in the literature include the microstrip resonator, cavity resonator, and transmission line dispersion methods. ${ }^{[7,9,26-29]}$ In this work, a microstrip T-resonator approach was used.

The fabricated T-resonator, generated with the electroless $\mathrm{Cu}$ deposition process on a single sheet of Teslin ${ }^{\circledR}$ paper (average paper thickness $=260 \mu \mathrm{m}$ ), is shown in Fig. 4(a). The T-resonator possessed a stub length of $63.2 \mathrm{~mm}$. The measured insertion loss (S21) as a function of frequency is shown in Fig. 4(b). As expected, resonances were detected at odd multiples of approximately $850 \mathrm{MHz}$, which included the 800 - $900 \mathrm{MHz}$ RFID and $2.4 \mathrm{GHz}$ WLAN bands. The permittivity and loss tangent values of the Teslin ${ }^{\circledR}$ paper, obtained with the aid of Eqs. (1)-(7), are plotted as a function of frequency in Figs. 4(c) and 4(d), respectively. The relative permittivity of the Teslin ${ }^{\circledR}$ paper was found to be $2.16 \pm 0.03$ over the frequency range of $0.85-7.74 \mathrm{GHz}$. This value is not far from the value of low-frequency relative permittivity reported for polyolefin $(2.3){ }^{[37]}$ The loss tangent of the Teslin ${ }^{\circledR}$ paper varied from $0.012-0.024$ over the measured frequency range, which was $3-5$ times lower than has been reported for standard cellulose-based paper. ${ }^{[5]}$ This latter result was promising for the generation of efficient (high quality factor) antennas and passive microwave components.

\subsection{4 GHz Monopole Design and Characterization}

A schematic illustration of the monopole antenna design used in this work is shown in Fig. 5(a). This design involved a coplanar waveguide feed and a meandered inductive load in order to shorten the overall antenna size. The overall size of the device was $2.3 \mathrm{~cm} \times 3 \mathrm{~cm}$, which corresponded to $0.18 \lambda \times 0.24 \lambda$ at $2.4 \mathrm{GHz}$ (and a $28 \%$ reduction in length over a standard $\lambda / 4$ monopole). The antenna performance was simulated using the dispersion model created for the Teslin ${ }^{\circledR}$ paper in Ansoft's HFSS frequency domain solver. The simulated return loss, displayed in Fig. 6, yielded a center frequency of $2.45 \mathrm{GHz}$ and an impedance bandwidth of $450 \mathrm{MHz}$.

The catalyst-based $\mathrm{Cu}$ deposition process, and the inkjet printing of Ag nanoparticle ink, were used to fabricate such 2.4 GHz monopoles on Teslin ${ }^{\circledR}$ paper for comparison of antenna performance. The $\mathrm{Cu}$ antenna was fabricated using electroless $\mathrm{Cu}$ deposition for $50 \mathrm{~min}$. The $\mathrm{Ag}$ antenna was generated via inkjet printing of 5 layers of the nanoparticle ink followed by thermal treatment at $120^{\circ} \mathrm{C}$ for $2 \mathrm{~h}$ in air. The fabricated $\mathrm{Cu}$ and $\mathrm{Ag}$ antennas are shown in Fig. 5(b). A conductive silver-bearing epoxy was used to attach the SMA connectors to both antennas for measurements. The return losses of both antennas, measured in an anechoic chamber, were compared with the simulated results (Fig. 6). Good agreement was obtained between the simulated and the measured values for the fabricated $\mathrm{Cu}$ and $\mathrm{Ag}$ antennas (i.e.,
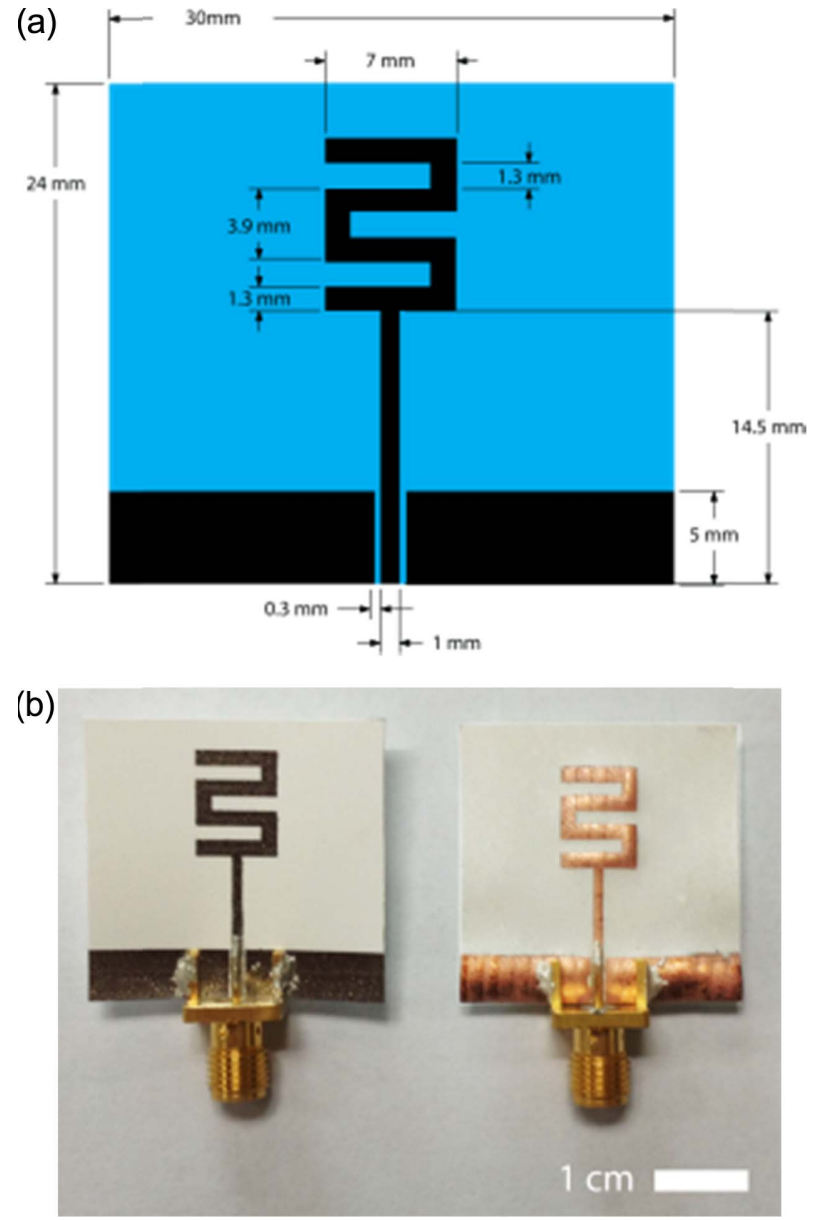

Fig. 5. (a) Schematic illustration of the $2.4 \mathrm{GHz}$ meander monopole. (b) Optical images of the fabricated $\mathrm{Ag}$ (left) and $\mathrm{Cu}$ (right) monopoles on Teslin ${ }^{\mathbb{B}}$ paper.

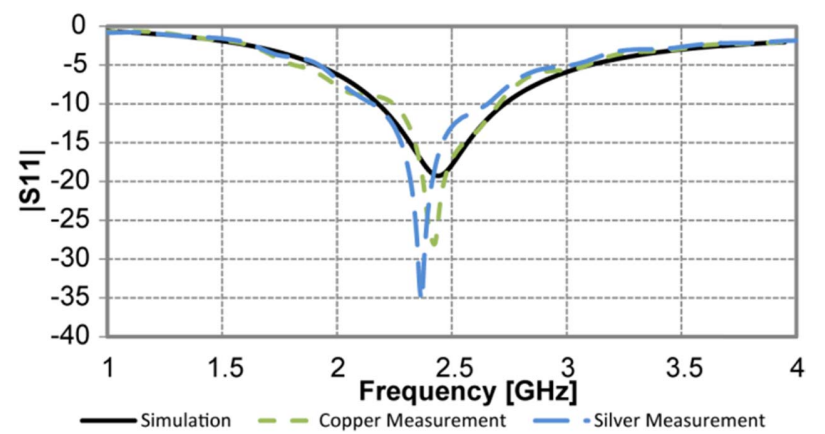

Fig. 6. Simulated and measured insertion losses ( 111 values) of the meander monopoles.

the measured resonant frequencies of the $\mathrm{Cu}$ and $\mathrm{Ag}$ antennas were 2.42 and $2.39 \mathrm{GHz}$, respectively, and the simulated resonant frequency was $2.45 \mathrm{GHz}$ ).

Measured and simulated antenna radiation patterns are shown in Fig. 7. The measured H-Plane and E-Plane patterns for the $\mathrm{Cu}$ and $\mathrm{Ag}$ monopole antennas were very similar. 
(a)

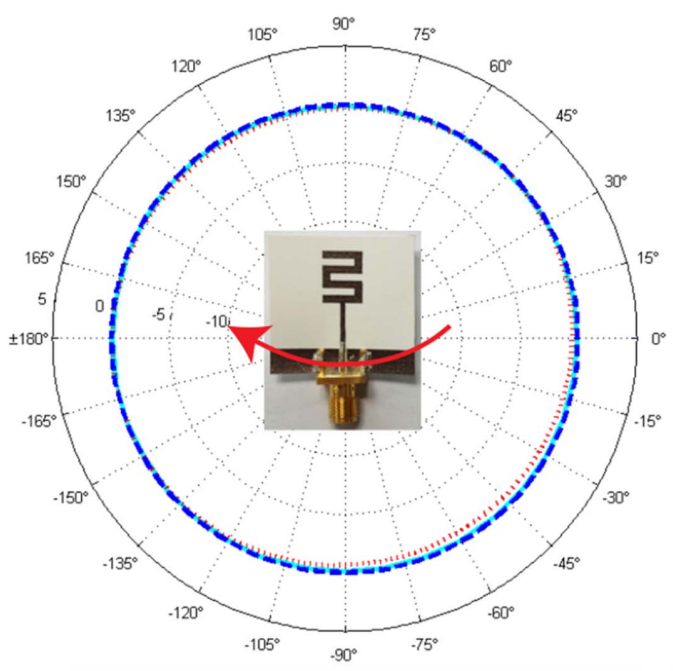

(b)

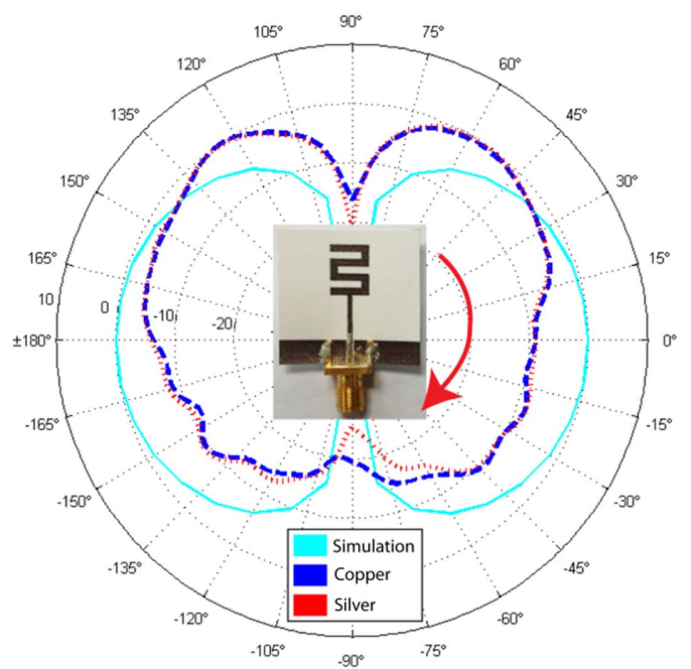

Fig. 7. (a) H-Plane radiation pattern, and (b) E-Plane radiation pattern obtained from simulation and from measurements of the $\mathrm{Cu}$ and $\mathrm{Ag}$ monopole antennas.

Reasonably good agreement was also obtained between these measured patterns and the simulated pattern. (Note: the effects of the connector and cable were not considered in the simulations, due to limited available computational time. These effects may be responsible for the modest disagreements between the simulated and measured E-Plane patterns.)

\section{CONCLUSIONS}

A scalable inkjet-based patterning process for generating Cu-based passive microwave components on flexible, recyclable $\left(\right.$ Teslin $\left.^{\circledR}\right)$ paper, that avoids nozzle-clogging problems and costs associated with noble metal particlebased inks, has been demonstrated. With this process, a tailored, homogeneous (single phase) catalyst-bearing solution is first inkjet printed in a desired pattern onto the Teslin ${ }^{\circledR}$ paper. The catalyst-bearing paper is then immersed in a copper electroless deposition solution at room temperature to yield copper films with the inkjet-derived pattern. The resulting compact and conformal copper films possessed thicknesses, and associated sheet resistances, that could be adjusted via control of the electroless deposition time. Unlike $\mathrm{Ag}$ films generated via inkjet printing of nanoparticle-based inks, post-deposition thermal treatments were not required to generate conductive patterns. After evaluating the relative permittivity and loss tangent of the Teslin ${ }^{\circledR}$ paper, a $2.4 \mathrm{GHz}$ meandering monopole antenna was designed to evaluate the microwave performance of such patterned $\mathrm{Cu}$ films on this paper. Measurements of insertion losses and radiation patterns revealed similar performance between antennas generated via this $\mathrm{Cu}$ electroless deposition-based process and via inkjet printing of a relatively expensive Ag nanoparticlebased ink. This all-solution-based copper patterning approach may be tailored for other flexible, low-temperature, inexpensive substrates and could be used to fabricate a variety of patterned RF devices.

\section{ACKNOWLEDGEMENTS}

The research of YF and KHS was supported by the U.S. Air Force via Award No. FA9550-09-1-0669. The research of WBG was supported by the U.S. Air Force via Award No. FA9550-10-1-0555. The research of BSC, SK, and MMT was supported by the U.S. National Science Foundation via Award No. 0801798. The research of TL was supported by the New Energy and Industrial Technology Development Organization, Japan via Award No. 09E5200d.

\section{REFERENCES}

1. A. Kamyshny, J. Steinke, and S. Magdassi, The Open Appl. Phys. J. 4, 19 (2011).

2. V. Subramanian, The Chemistry of Inkjet Inks (ed. S. Magdassi), p. 283, World Scientific, New Jersey (2010).

3. E. Tekin, P. J. Smith, and U. S. Schubert, Soft Matter 4, 703 (2008).

4. P. Calvert, Chem. Mater. 13, 3299 (2001).

5. B. S. Cook, and A. Shamim, IEEE Trans. Antennas Propag. 60, 4148 (2012).

6. H.-Y. Tseng and V. Subramanian, Organic Electron. 12, 249 (2011).

7. G. Shaker, A. Rida, S. Safavi-Naeini, M. M. Tentzeris, and S. Nikolaou, Proc. 5th Euro. Conf. Antennas Propag. (EUCAP), p. 3001 (2011).

8. L. Yang, R. W. Zhang, D. Staiculescu, C. P. Wong, and M. M. Tentzeris, IEEE Antennas Wireless Propag. Lett. 8, 653 (2009).

9. A. Rida, L. Yang, R. Vyas, and M. M. Tentzeris, IEEE 
Antennas Propag. Mag. 51, 13 (2009).

10. J. Perelaer, M. Klokkenburg, C. R. Hendriks, and U. S. Schubert, Adv. Mater. 21, 4830 (2009).

11. Y. Noguchi, T. Sekitani, T. Yokota, and T. Someya, Appl. Phys. Lett. 93, 043303 (2008).

12. T. Sekitani, Y. Noguchi, Y. Zschieschang, H. Klauk, and T. Someya, Proc. Nat. Acad. Sci. USA 105, 4976 (2008).

13. Y. Noguchi, T. Sekitani, and T. Someya, Appl. Phys. Lett. 89, 253507 (2006).

14. V. Subramanian, J. M. J. Frechet, P. C. Chang, D. C. Huang, J. B. Lee, S. E. Molesa, A. R. Murphy, D. R. Redinger, and S. K. Volkman, Proc. IEEE 93, 1330 (2005).

15. T. H. J. van Osch, J. Perelaer, A. W. M. de Laat, and U. S. Schubert, Adv. Mater. 20, 343 (2008).

16. S. H. Ko, H. Pan, C. P. Grigoropoulos, C. K. Luscombe, J. M. J. Frechet, and D. Poulikakos, Nanotechnol. 18, 345202 (2007).

17. J. Cheon, J. Lee, and J. Kim, Thin Solid Films 520, 2639 (2012).

18. S. Magdassi, M. Grouchko, and A. Kamyshny, Mater. 3, 4626 (2010).

19. I. Kim and J. Kim, J. Appl. Phys. 108, 102807 (2010).

20. M. Grouchko, A. Kamyshny, and S. Magdassi, J. Mater. Chem. 19, 3057 (2009).

21. P. Kanninen, C. Johans, J. Merta, and K. Kontturi, J. Coll. Inter. Sci. 318, 88 (2008).

22. S. M. Bidoki, D. M. Lewis, M. Clark, A. Vakorov, P. A. Millner, and D. McGorman, J. Micromech. Microeng. 17, 967 (2007).

23. X. Xia, C. Xie, S. Cai, Z. Yang, and X. Yang, Corr. Sci. 48, 3924 (2006).

24. A Description of Characteristics of Printable Fluids for the Dimatix DMP-2800 Inkjet Printer Can be Found at: www. fujifilmusa.com/products/industrial_inkjet_printheads/deposition- products/dmp-2800/index.html

25. C. Kim, M. Nogi, K. Suganuma, Y. Saitou, and J. Shirakami, RSC Adv. 2, 8447 (2012).

26. K. P. Latti, M. Kettunen, J. P. Stoem, and P. Silventoinen, IEEE Trans. Instrument. Measurement 56, 1845 (2007).

27. D. Markovic, B. Jokanovic, M. Marjanovic, and M. Djordjevic, Instrument. Measurement Technol Conf. Proc. p. 1, IMTC, IEEE (2007).

28. A. R. Fulford and S. M. Wentworth, Microwave Optical Technol. Lett. 47, 14 (2005).

29. R. K. Hoffmann, Handbook of Microwave Integrated Circuits. Artech House, Norwood, MA (1987).

30. R. W. Pekala, R. A. Schwarz, R. G. Swisher, R. C. Wang, R. O. Ondeck, and M. O. Okoroafor, Polymer Mater. Sci. Eng. 76, 593 (1997).

31. W. J. Dressick, C. S. Dulcey, J. H. Georger, Jr., G. S. Calabrese, and J. M Calvert, J. Electrochem. Soc. 141, 210 (1994).

32. M. Charbonnier, M. Romand, G. Stremsdoerfer, and A. Fares-Karam, Recent Res. Dev. Macromol. Res. 4, 27 (1999).

33. Y. Shacham-Diamand and S. Lopatin, Electrochim. Acta 44, 3639 (1999).

34. L. Xu, J. Liao, L. Huang, D. Ou, Z. Guo, H. Zhang, C. Ge, N. Gu, and J. Liu, Thin Solid Films 434, 121 (2003).

35. Z. Bao, E. M. Ernst, S. Yoo, and K. H. Sandhage, $A d v$. Mater. 21, 474 (2009).

36. Y. Fang, Y. D. Berrigan, Y. Cai, S. R. Marder, and K. H. Sandhage, J. Mater. Chem. 22, 1305 (2012).

37. J. Baker-Jarvis, B. Riddle, and M. Janezic, NIST Tech. Rept. No. 1512 (1999). 